\title{
Isparta Havzasının 1D Doğrusal Olmayan Zemin Tepki Analizi Yöntemi ile Değerlendirilmesi; 1914 Burdur (Ms: 7.0) Deprem Senaryosu
}

\begin{abstract}
Ali Silahtar ${ }^{1, *}$
${ }^{1}$ Sakarya Üniversitesi, Mühendislik Fakültesi, Jeofizik Mühendisliği Bölümü, 54050, Sakarya.

Özet

Depremlerin meydana getirdiği yapı hasarlarının sadece depremin fiziksel özelliklerinden değil aynı zamanda zeminin özelliklerine de bağll olduğu bilinmektedir. Bu durum zemin tepkisinin kuvvetli yer hareketi öncesi belirlenmesini deprem mühendisliği ve sismolojinin ana hedeflerinden birisi haline getirmiştir. Bu çalışmada, belirlenen 24 noktada kayma dalgası (Vs) ve sondaj verileri kullanılarak Türkiye'nin en önemli tektonik elemanlarından birinin merkezinde yer alan Isparta ovasinın zemin tepkisinin öngörülmesi hedeflenmiștir. Türkiye Bina Deprem Yönetmeliği (TBDY-2018) zemin sinıflama kriterlerine göre ZC ve ZD zemin grupları karakterize edilen çalışma alanında 1 boyutlu doğrusal olmayan zemin tepki analizi yaklaşımı DEEPSOIL programı kullanılarak gerçekleștirilmiștir. Mw:6.9 İrpinia kuvvetli yer hareketi kaydı kullanılarak yapılan çözümlemede çalıșma alanının en büyük yer ivmesi (Pga) ve spektral ivme ( $\mathrm{Sa}$ ) dăğlım haritası oluşturulmuştur. Çalışma alanında yüzeydeki Pga değerleri 0.28-0.41 $g$ aralığında, maksimum Sa değerleri ise 0.77-1.82 g aralığında dağılım gösterdiği tespit edilmiştir. Ayrıca havza içerisinde birbirine dik iki kesit üzerinde Pga ve Vs30 arasındaki uyum irdelenmiştir. Elde edilen sonuçlar şehir merkezi ve yeni yapılaşma alanlarının yoğun olduğu Çünür bölgesinde zeminin kuvvetli yer hareketinin etkilerini önemli bir şekilde arttıracă̆ını göstermiştir.
\end{abstract}

\section{$\underline{\text { Anahtar Sözcükler }}$}

Zemin Tepkisi, En Büyük Yer İvmesi (Pga), 1D Doğrusal Olmayan Zemin Tepki Analizi, Spektral İvme (Sa), Isparta

\section{Assessment of Isparta Basin by Using 1D Nonlinear Site Response Analysis Approach; 1914 Burdur (Ms: 7.0) Earthquake Scenario}

\begin{abstract}
It was known that building damage caused by earthquakes depends not only on the physical characteristics of the earthquake but also on the characteristics of the soil. This fact has determined soil response before strong ground motion is one of the main objectives of earthquake engineering and seismology. In this study, the main objective is to predict the soil response of the Isparta basin, Isparta, located in the center of one of Turkey's most important tectonic elements. It uses shear wave velocity (Vs) and borehole data at 24 points. The soil of the study area was classified as ZC and ZD soil groups according to the Turkish Building Earthquake Code-2018 (TBEC-2018) soil classification criteria, and its 1D Nonlinear site response analysis approach was carried out using the DEEPSOIL program in the study area. In the analysis, $6.9 \mathrm{Mw}$ Irpinia strong ground motion record was used and the largest peak ground acceleration (Pga) and spectral acceleration ( $\mathrm{Sa}$ ) maps of the study area were created. Pga values in the study area were determined in the range of 0.28-0.41 $\mathrm{g}$ and $\mathrm{Sa}$ values in the range of 0.77-1.82 $\mathrm{g}$. In addition, the coherence between $2 \mathrm{D}$ sections and Pga and Vs30 was examined. The obtained results were showed that the soil would significantly increase the effects of strong ground motion in the Çünür region where the city center and new settlement areas are dense.
\end{abstract}

Keywords

Site Response, Peak Ground Acceleration (Pga), 1D Nonlinear Site Response Analysis, Spectral Acceleration (Sa), Isparta

\section{Giriş}

Kalabalık yerleşim merkezlerinin yakınında meydana gelen depremler, can ve mal kayıpları ile sosyoekonomik hayatta önemli kesintilere neden olmaktadırlar (Coburn ve Spence 2002). Bu depremler arasında Mexico City’de 1985 Michoacan (Mw:8.2), Amerika Birleşik Devletleri'ndeki 1994 Northridge (Mw:6.7), Japonya'daki 1995 Kobe (Mw:7.2), Türkiye'deki 1999 İzmit (Mw:7.4) ve Nepal'deki 2015 Gorkha (Mw:7.8) depremleri öncelikli olarak gösterilebilir. Depremler sonrası yapılan araştırmalar yerel jeolojinin hasar dağılımı üzerinde etkili olduğunu göstermektedir (Şafak 2001; Goto vd. 2005). Bilindiği gibi deprem dalgaları yer içerisinde kaya ortamında kolayca yayılabilmesine karşın yüzeye yakın sı̆̆ kısmın zemin koşulları bu yayılımı olumsuz şekilde etkileyebilmektedir. Sı̆̆ kısımdaki düşük sismik hızlı jeolojik malzemeler dalga hızını düşürmesi nedeniyle yer hareketini güçlendirmede kritik bir öneme sahiptir (Kramer 1996). Dolayısıyla, yerel saha koşulları kuvvetli yer hareketinin genliği, frekans içeriği ve süresi gibi öncelikli bileşenlerini önemli ölçüde etkiler (Rayhani vd. 2008; Gautam vd. 2016; Sana vd. 2019). 
$\mathrm{Bu}$ nedenle karmaşık jeoloji ile karakterize edilen alanlarda yerel zemin tepkisi kavramı deprem zararlarının etkilerinin azaltılmasında ve depreme dayanıklı yapı tasarımında özel bir öneme sahiptir. Bu bağlamda gerek deprem mühendisleri ve gerekse sismologlar kuvvetli yer hareketi esnasında zemin tepkisinin tahmin edilmesi konusunda çeşitli zemin tepki analizi (ZTA) yöntemleri geliştirmişlerdir.

Zaman ve frekans ortamında çözüm sağlayan ZTA yöntemlerinden eşdeğer doğrusal ve doğrusal olmayan zemin tepki analizi (DOZTA) en çok tercih edilen yöntemlerdendir. Bu yöntemlerden pratik bir şekilde sonuç veren eşdeğer doğrusal zemin tepki analizi yaygın kullanılmaktadır. Analizin daha az parametre gerektirmesi ve kolay hesaplanabilirliği yöntemi öne çıkarmıştır. Buna karşın yöntem iki açıdan kısıtlama göstermektedir. Zeminde oluşan toplam gerilmeyi dikkate alan yöntemde, frekans aralığ 1 geniş alındığından dolayı en büyük pik ivme (Yoshida 1994; Yoshida ve Iai 1998) değerleri olduğundan biraz daha büyük hesaplanmaktadır. Ayrıca Hashash vd. (2010) tarafından ifade edildiği gibi her bir tabakanın rijitidesi ve sönümünün doğru bir şekilde hesaplanamadığı durumlarda zemin tepkisi doğru bir şekilde hesaplanamayabilir. Diğer taraftan zaman ortamında çözümleme imkanı sunan DOZTA, zeminin doğasında olan doğrusal olmama durumunu (Arslan ve Siyahi 2006) ve zeminin histerik gerilme-deformasyon tepkisini dikkate alması nedeni ile (Bolisetti vd. 2014) eşdeğer doğrusal yönteme kıyasla daha gerçekçi ve kesin sonuçlar üretir. Ancak yetersiz doküman ve yanlış parametre kullanımı yöntemin pratikte kullanımını sınırlamıştır. Literatürde her iki yaklaşıma dair teorik ve saha uygulaması üzerine birçok araştırma bulunmaktadır (Kramer 1996; Assimaki vd. 2000; Darendeli 2001; Park ve Hashash 2008; Hashash vd. 2010; Kaklamanos vd. 2015; Basu vd. 2019). Özellikle yoğun sismik aktiviteli Nepal'deki Katmandu (Gautam vd. 2016), Türkiye'deki Elazı̆̆ (Sönmezer vd. 2019), Hindistan'daki Kashmir ovasında (Sana vd. 2019) yerleşim merkezlerini de kapsayan çalışmalardan elde edilen sonuçlar deprem güvenlikli alanların tahmin edilmesine sağlayacağı katkı açıkça vurgulanmıştır.

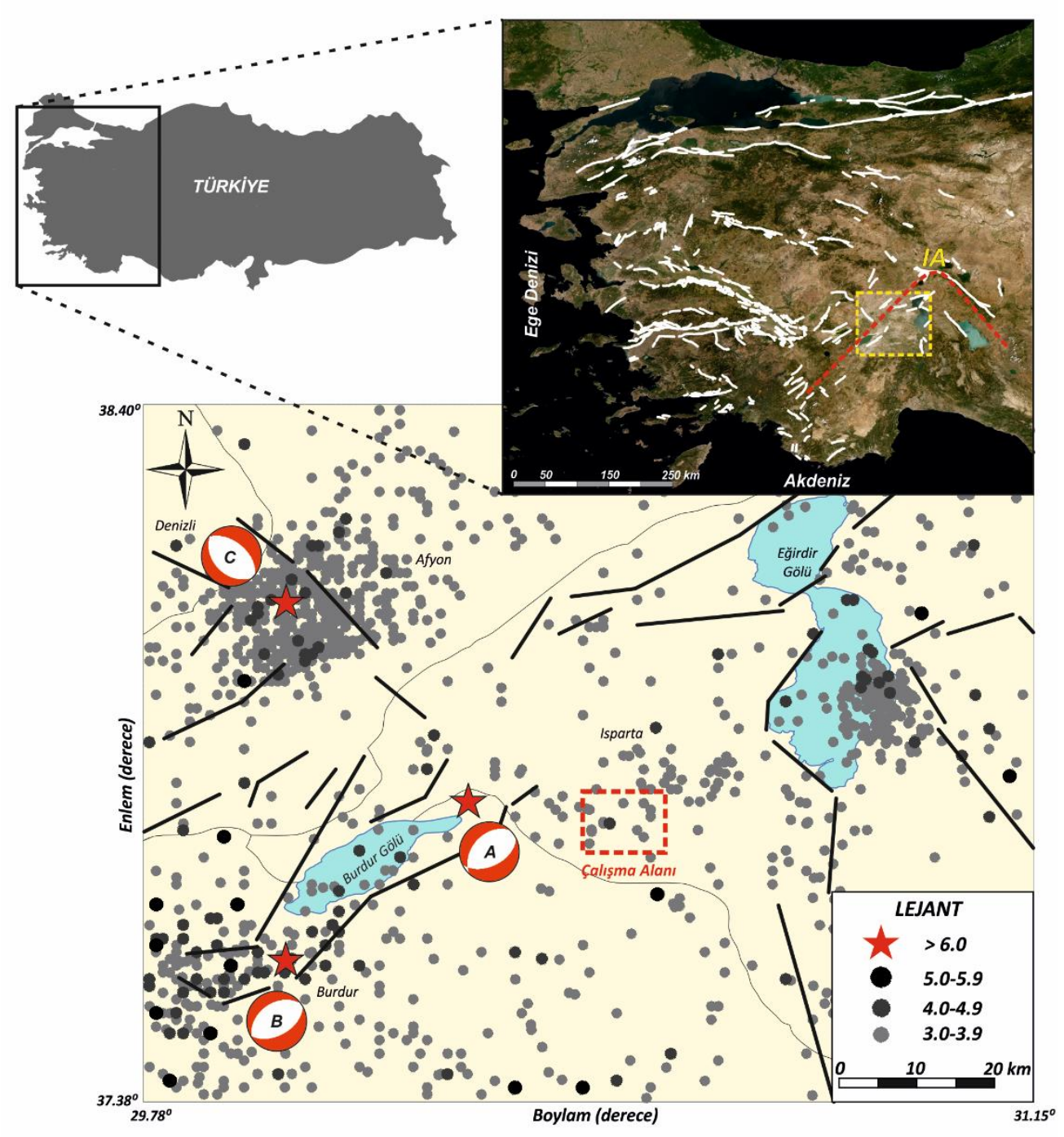

Şekil 1: Isparta AçıSı (IA) ve çevresinin mikro deprem ve tektonik haritası. A) 1914 Burdur depremi (Ms: 7.0), B) 1971 Burdur depremi (Ms: 6.2), C) 1995 Dinar depremi (Ms:6.1) 
Türkiye sismisitesi yüksek, yıkıcı tektonik zonları içerisinde barındıran bir deprem ülkesidir. Fethiye-Burdur Fay Zonu (FBFZ) ile Akşehir Fay Zonu (AFZ) arasında bir kavşak noktası olan Isparta Açısı (Isparta büklümü) (IA) bu tektonik yapının en önemli elemanlarından birisidir. Nitekim geçmiş yıllarda meydana gelen 1914 Burdur (Ms:7.0), 1971 Burdur (Ms:6.2), 1995 Dinar (Mw:6.4) gibi yıkıcı depremler bunun bir göstergesidir (Şekil 1). Buna karşın bölge içerisinde oldukça sınırlı sayıda zemin tepki araştırması olmakla birlikte bu çalışmalar yoğunluklu olarak Dinar havzası ile sınırlıdır (Ansal vd. 2001; Kanlı vd. 2006; Hasal ve İyisan 2014; Khanbabazadeh vd. 2016). Alüvyal kalınlığın yaklaşık 500 metreye ulaştı̆̆ Isparta havzasında (Silahtar 2018) ise herhangi bir zemin tepki çalışması olmayışı dikkat çekicidir. Buna ek olarak havzaya dair bir diğer önemli bilgi ise ovadaki kalın alüvyon istifin etek, göl, nehir, geçiş (delta) çökellerinden (Kazanc1 ve Karaman 1988; Kazanc1 1990; Görmüş vd. 2005) meydana gelmesidir. Benzer alüvyal istifin gözlemlendiği gevşek zeminlerin sismik dalgaları güçlü bir şekilde arttırabileceği ve beraberinde zeminde yüksek ivme değerlerine neden olabileceği birçok araştırmada irdelenmiştir (Vucetic ve Dobry 1991; Özel ve Sasatani 2004; Selçuk ve Aydın 2012; Akın vd. 2016). Dolayısıyla bu tür alanların zemin tepkisinin araştırılması deprem zararlarını azaltmada önemli rol oynamaktadır. Bu çalışmada bir boyutlu (1D) zemin tepki analizi tekniği kullanılarak Isparta ve çevresinin Pga ve Sa dağılım haritaları belirlenerek yerel zemin koşulları ile uyumu irdelenmiştir.

\section{1. Çalışma Alanın Jeolojisi ve Tektoniği}

Türkiye aktif tektonik rejime sahip olan doğu Akdeniz bölgesinde yer almaktadır. Arap levhasının doğudaki Avrasya levhasıyla çarpışması ve Afrika levhasının batıda Anadolu bloğuna dalması Anadolu bloğunu Kuzey ve Doğu Anadolu Fayları (KAF ve DAF) boyunca batıya doğru itmektedir. Bu tektonik yapı bölgede yoğun deprem etkinliğine neden olmuştur. Çalışma alanındaki deprem etkinliği batıda FBFZ ve doğuda AFZ tarafindan kontrol edilmektedir. Bu faylar Eğirdir Gölü'nün kuzeyindeki Sultandağı Fayı ile birleşir ve Isparta Açısı (IA) olarak bilinen üçgen şekilli yapıyı oluşturur (Blumenthal 1963). Isparta havzası, IA'nın yaklaşık kuzey merkezinde yer almaktadır (Şekil 1).

Şekil 1 Isparta ve yakın çevresinde yer alan bölgenin sismisitesini göstermektedir. Şekilden görüleceği üzere bölge yoğun bir sismisiteye sahiptir. Mikro deprem haritası, depremlerin merkez üslerinden bazılarının Isparta yerleşim bölgesinde meydana geldiğini göstermektedir. Bu durum, Koçyiğit ve Özacar (2003) tarafından belirtilen yerleşim alanındaki yerel faylara ile açıklanabilir.

Isparta açısının kuzeyinde yer alan çalışma alanı, bölgesel jeoloji ve tektoniğin etkisinde Mesozoyik ve Senozoyik yaşı 1 Otokton özellikler ihtiva eden çeşitli kayaç topluluklarından (Söbüdağ Kireçtaşı Üyesi, Çiğdemtepe Kireçtaşı, Güneyce Formasyonu) oluşmaktadır. Çalıșma alanı içerisinde yüzeylenme veren ve otokton özellik gösteren kaya birimleri yaşlıdan genç birimlere doğru; Üst kretase yaşlı Davras grubu ve Çiğdemtepe Kireçtaşı, Paleosen yaşlı Kızılkırma formasyonu, Orta Eosen yaşlı Isparta filişi, Alt Miyosen yaşlı Güneyce formasyonu, Pliyosen yaşlı gölcük volkanitleri ve Piroklastiklerden oluşmakta olup tüm bu formasyonları uyumsuz olarak üzerleyen Kuvaterner yaşlı alüvyon malzemelerden meydana gelmektedir (Akbulut 1980; Karaman vd. 1988; Görmüş ve Özkul 1995; Poisson vd. 2003) (Şekil 2)

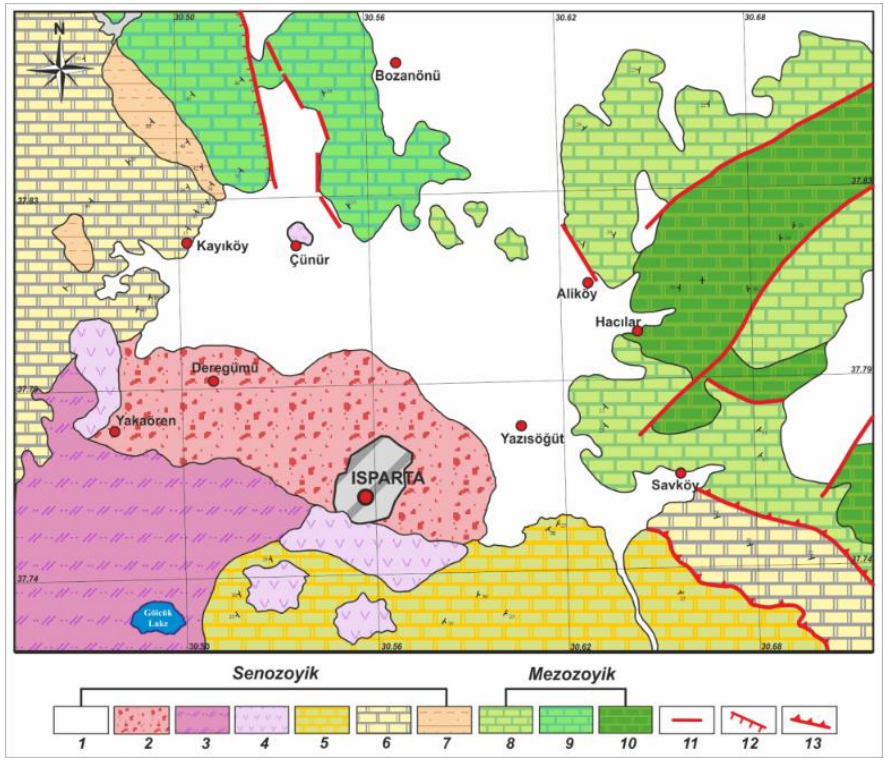

Şekil 2: Çalışma alanı jeoloji haritası. 1: Alüvyon, 2: Piroklastikler, 3: Volkanoklastikler, 4: Gölcük Fm., 5: Güneyce Fm., 6: Kayıköy Fm. (Isparta Filişi), 7: Kızılkırma Fm., 8: Çiğdemtepe Fm., 9: Söbüdağ Fm., 10: Menteşe Fm., 11: Normal fay, 12: Ters fay, 13: Bindirme fayı (Görmüş ve Özkul 1995; Poisson vd. 2003'den düzenlenmiştir) 


\section{Materyal ve Metot}

\subsection{D doğrusal olmayan zemin tepki analizi}

Zemin tepki analizi (ZTA) Kramer (1996) tarafından ifade edildiği gibi zeminin deprem sırasında serbest alan tepkisinin hesaplanması işlemidir. Bu hesaplamada yöntem düşey yönde yatay tabakalar içerisinde yayılım gösteren yatay kayma dalgalarını (SH) kullanır. Çeşitli zemin sınıflarının gerilme-deformasyon davranışının belirlenmesi üzerine başlayan deneyler (Seed ve Idriss 1970; Hardin ve Drnevich 1972), serbest alan tepki analizi süreci sönümleme eğrileri ve azalım modülünün iteratif olarak hesaplanması ile mühendislik uygulamalarında kullanılmaya başlamıștır. Daha sonra zeminin lineer olmayan histerik davranışının modellemesi ve zemin tepki analizlerinin hesaplaması adına farklı zeminler için hiperbolik yükleme-boşaltma eğrileri türetilmiştir (Vucetic ve Dobry 1991; Matasovic 1993; Hashash ve Park 2001; Kwok vd. 2007; Phillips ve Hashash 2009; Hashash vd. 2017). Zeminin döngüsel gerilme-deformasyon tepkisini daha gerçekçi yansıtan doğrusal olmayan analiz için PROSHAKE, DEEPSOIL, DESRA, LS-DYNA gibi programlar geliştirilmiş ve yöntem uygulaması yaygınlaşmıştır.

ZTA problemlerinin çözümlemelerinde zaman ve frekans ortamı analizleri kullanılmaktadır. Bu yöntemlerden özellikle frekans ortamında çözümleme yapan eşdeğer doğrusal zemin tepki analizi yaklaşımı kolay uygulanabilirliği ve kullanımı ile oldukça popülerdir. Ancak bilindiği üzere ZTA zeminin doğrusal olmayan gerilme-deformasyon modelinden önemli bir şekilde etkilenir (Phillips ve Hashash 2009; Kaklamanos vd. 2015; Régnier vd. 2018). Dinamik analiz için zeminin gerilme-deformasyon davranışının doğrusal olmaması, zeminin kayma modülünün sürekli değiştiği anlamına gelir (Arslan ve Siyahi 2006). Zeminin bu histeretik döngüsel davranışı sismik aktivite esnasında belirli bir alan için genlik fonksiyonun değişeceğini ifade eder. Bununla birlikte deformasyon oranı yüksek zeminlerde veya yüksek sismik aktiviteli kaya ortamı gibi durumlarda dinamik zemin özelliklerini doğrudan etkileyen rijitlik ve sönümleme davranışını temsil edilemeyebilir (Kramer 1996; Phillips ve Hashash 2009). Doğrusal olmayan yöntem toprağın histeretik gerilme-deformasyon tepkisini hesaba katarak sarsıntı sırasında kesme modülündeki ve sönüm oranındaki değişimi temsil edebilir. Bu bağlamda doğrusal olmayan analiz yaklaşımı eşdeğer doğrusal yöntemden daha gerçekçidir (Hosseini ve Pajouh 2012; Bolisetti vd. 2014). Doğrusal olmayan zemin tepki analizi yaklaşımında zaman ortamında dinamik hareket denklemi şu şekilde çözülür;

$$
[\mathrm{M}]\{\ddot{\mathrm{u}}\}+[\mathrm{C}]\{\dot{\mathrm{u}}\}+[\mathrm{K}]\{\mathrm{u}\}=-[\mathrm{M}]\{\mathrm{I}\} \ddot{\mathrm{u}}_{\mathrm{g}}
$$

Burada $[\mathrm{M}],[\mathrm{C}]$ ve $[\mathrm{K}]$ sırasıyla kütle, viskoz sönüm ve rijitlik matrisini ifade etmektedir. $\{\ddot{\mathrm{u}}\},\{\dot{\mathrm{u}}\},\{\mathrm{u}\}$ ise sirasıyla bağıl ivme, bağıl hız ve bağıl yer değiştirme vektörleridir. Son olarak $\left\{\ddot{u}_{g}\right\}$ indisi temel zemin kolonundaki ivme, $\{\mathrm{I}\}$ ise birim vektördür. Verilen eşitlikte $[\mathrm{M}],[\mathrm{C}]$ ve $[\mathrm{K}]$ matrisleri zemin katmanlarının değişen özellikleri kullanılarak toplanır. Çözümlemenin daha detaylı teorik altyapısı Hashash ve Park (2001); Phillips ve Hashash (2009); Hashash vd. (2010)'da detaylı bir şekilde irdelenmiştir.

Doğrusal olmayan zemin tepki analizinde zeminin kesme dayanımı ve sönüm katsayısı, zemin örneği için geliştirilen kesme deformasyonu ve temel zemin modeli ile ilgilidir. Bu konuda çeşitli basitleştirilmiş gelişmiş temel zemin modelleri yer almaktadır. Doğrusal olmayan zemin tepki analizinde döngüsel sarsıntı sırasında zeminin histerik davranışını tanımlamada, temel döngü eğrisi ve genişletilmiş yükleme-boşaltma Masing kurallarını (Matasovic 1993; Hashash ve Park 2001) kapsayan hiperbolik gerilme-deformasyon modeli (Kondner and Zelasko) kullanılır. Burada ifade edilen hiperbolik model yeniden düzenlenmiş MKZ (Matasovic-Kondner-Zelasko) modeli olarak bilinen iki denklem seti ile tanımlanmıştır. Bu denklemler $(2,3)$ temel zemin eğrisinde gerilme-deformasyon ilişkisini sırayla yükleme ve boşaltma-tekrar yükleme koşulları için tanımlar.

$$
\begin{aligned}
& \tau=\frac{\gamma \mathrm{G}_{0}}{1+\beta\left({ }^{\gamma} / \gamma_{\mathrm{r}}\right)^{s}} \\
& \tau=\frac{2 \mathrm{G}_{0}\left({ }^{-}-\gamma_{\mathrm{rev}} / 2\right)}{1+\beta\left({ }^{\gamma-\gamma_{\mathrm{rev}} / 2 \gamma_{\mathrm{r}}}\right)^{s}}+\tau_{\mathrm{rev}}
\end{aligned}
$$

Yukarda verilen eşitliklerde $\gamma$ kesme gerilimi, $\gamma_{\mathrm{r}}$ referans kesme gerilimi, $\gamma_{\mathrm{rev}}$ ters yöndeki kesme gerilimi, $\mathrm{G}_{0}$ başlangıç kesme modülünü temsil ederken $\beta$ ve s boyutsuz parametrelerdir.

\subsection{Doğrusal olmayan zemin tepki analizi parametreleri}

\subsubsection{Zemin verisi}

Isparta şehir merkezini kapsayan çalışmada zeminin dinamik özelliklerini belirlemede 24 noktada gerçekleştirilen yüzey dalgaları (ReMi) verileri ve bu noktalara yakın mevcut sondaj verileri kullanılmıştır (Şekil 3). 
Borcherdt (1994) yüzeydeki zeminin dinamik özelliklerinin ilk 30 metredeki tabakalaşmadan etkilendiğini, kuvvetli yer hareketi kayıtları ile ortaya koymuştur. Bir diğer taraftan deprem yönetmeliklerinde tasarım spektrumların çizilmesi sırasında zemin bağımlı spektral değerler zeminin ilk 30 metredeki büyütme katsayılarına bağlı olarak elde edilir. Bu nedenle bu çalışmada ilk 30 metreyi kapsayacak şekilde zeminin ilk 50 metrelik kısmı ele alınmıştır.

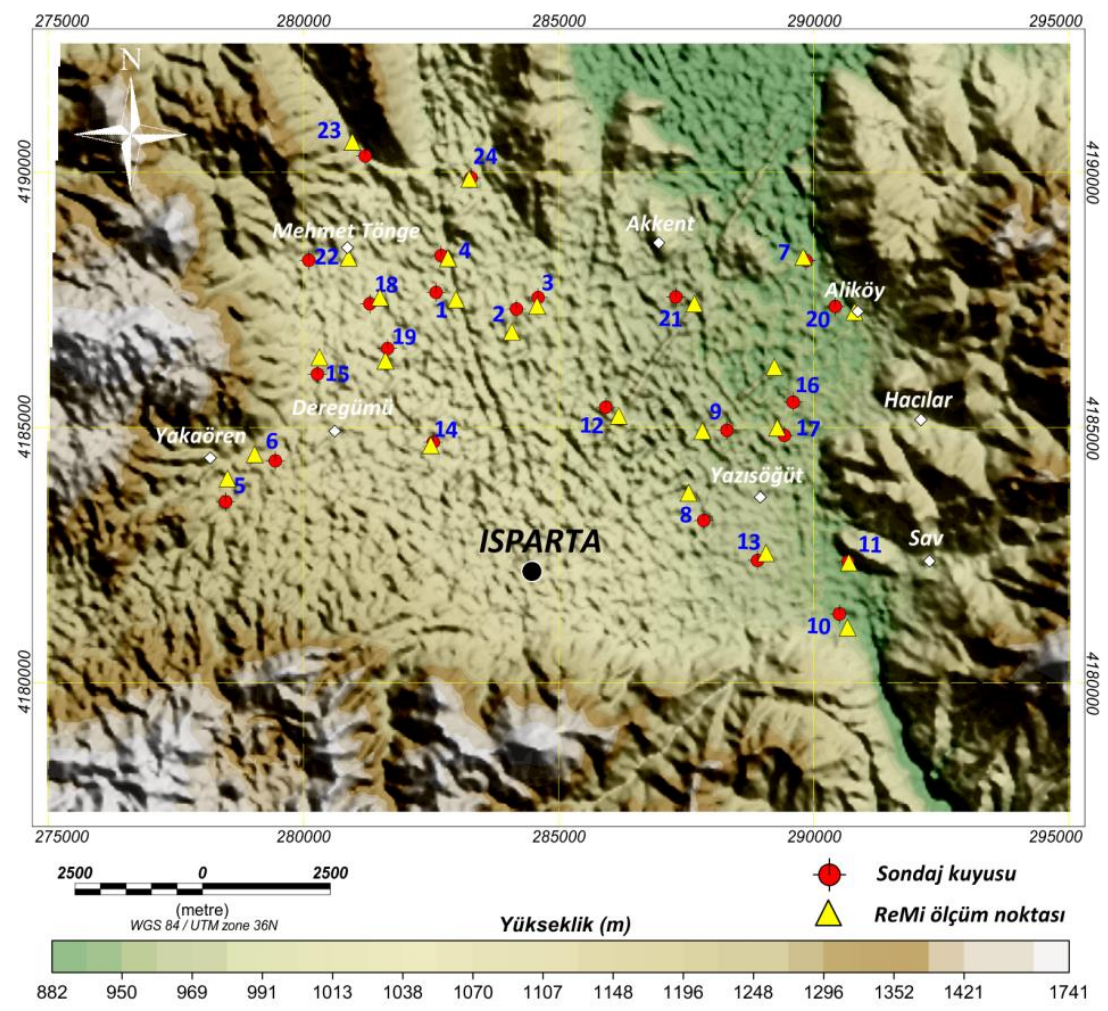

\section{Şekil 3: Veri kazanım noktaları}

ZTA'da tabakaların kayma dalgası hızının (Vs) belirlenmesinde ReMi yöntemi (Louie 2001) kullanılmıştır. Yüzey dalgalarının dispersiyon eğrisi analizine dayanan yöntem herhangi bir aktif kaynak gerektirmemektedir. Yeterli alıcı açılımı ve çevresel gürültünün kaydı ile 100 metre derinlik seviyesine kadar Vs hızının belirlenmesinde kullanılmaktadır. Daha geniş jeofon açılımı, daha düşük resonant frekanslı jeofon kullanımı ve daha yüksek enerjili çevresel gürültünün kullanılmasıyla daha derin seviyelerine kadar (Louie vd. 2017) kayma dalgası bilgisi elde edilebilir. Yöntem temel olarak iki prensibe dayanmaktadır. Birincisi standart sismik kırılma ekipmanı kullanarak doğal veya çevresel etmenlerden kaynaklı meydana gelmiş gürültünün kayıt edilmesidir. İkinci prensip ise iki boyutlu yavaşlık (hızın tersi)-frekans (p-f) dönüşümüyle Rayleigh dalgasını gürültü kayıtlarından ayırıp görünür hıza karşılık gerçek faz hızının elde edilmesidir (Şekil 4).

Bir diğer önemli parametre olan zemin türü ve bileşenleri Devlet Su İşleri 18. Bölge Müdürlüğü tarafından gerçekleştirilen sondaj verilerinden elde edilmiştir. Bu veriler neticesinde çalışma alanının ilk 50 metresinin killi-siltli çakıl (GC-GM), kötü derecelenmiş çakıl (GP), kumlu çakıl (sG), killi kum (SC), yüksek ve düşük plastisiteli kil (CL$\mathrm{CH}$ ) ve yer yer tüf-tüfit birimlerden oluştuğu görülmektedir (Şekil 5). Yerinde ve laboratuvar deneylerinden jeolojik birimlerin yoğunluklarının yaklaşık $16.4 \mathrm{kN} / \mathrm{m}^{3}$ ile $21.8 \mathrm{kN} / \mathrm{m}^{3}$ aralığında olduğu tespit edilmiştir. Kil-silt içerikli tabakaların sönüm eğrileri üzerinde etkili plastisite indeksi (PI) ise çalışma alanında yaklaşık \%8-20 aralığındadır. Ayrıca çalışma alanını temsil eder nitelikteki bazı veri kazanım noktalarındaki (Şekil 5) modelleme parametreleri Tablo 1' de verilmiştir. 


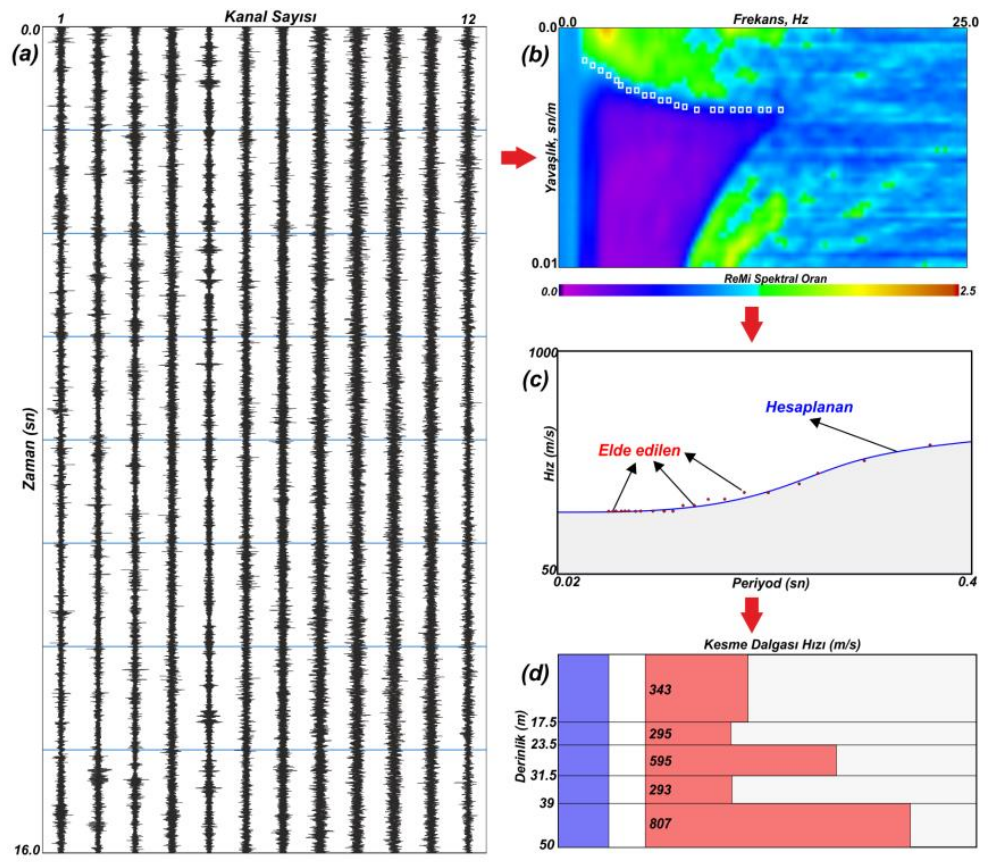

Şekil 4: ReMi veri işlem aşamaları a) gürültü kaydı, b) dispersiyon eğrisi seçimi, c) ters çözüm, d) 1D derinlik-kayma dalgası hız kesiti (veri işlem örneği 6 numaralı veri kazanım noktasına aittir)

Tablo 1: Çalışma alanını temsil eder nitelikte bazı veri kazanım noktalarındaki ZTA model parametreleri

\begin{tabular}{|c|c|c|c|c|c|}
\hline Kuyu No & Derinlik (m) & Zemin Türü & $\rho\left(\mathrm{kN} / \mathrm{m}^{3}\right)$ & PI & $\tau(\mathrm{kPa})$ \\
\hline \multirow{5}{*}{7} & $0.00-10.5$ & SC & 17.3 & $\mathrm{NP}$ & 153.2 \\
\hline & $10.5-14.5$ & $\mathrm{SC}$ & 17.3 & NP & 254.3 \\
\hline & $14.5-24.5$ & GC & 18.2 & NP & 356.3 \\
\hline & $24.5-41.5$ & GC & 18.2 & NP & 464.7 \\
\hline & $41.5-50.0$ & Tüf-Tüfit & 20.8 & 16 & 1679.4 \\
\hline \multirow{4}{*}{8} & $0.00-8.00$ & $\mathrm{CL}$ & 16.9 & 10 & 111.4 \\
\hline & $8.00-21.5$ & GW & 19.4 & NP & 467.6 \\
\hline & $21.5-35.0$ & $\mathrm{CL}$ & 17.1 & 12 & 379.8 \\
\hline & $35.0-50.0$ & GW & 20.2 & NP & 1045.0 \\
\hline \multirow{4}{*}{10} & $0.00-14.5$ & SM & 16.8 & NP & 190.6 \\
\hline & $14.5-30.0$ & GW & 18.4 & NP & 454.1 \\
\hline & $30.0-47.0$ & GC & 19.6 & NP & 761.6 \\
\hline & $47.0-50.0$ & GC & 21.8 & NP & 1491.5 \\
\hline \multirow{3}{*}{12} & $0.00-11.0$ & GM & 18.0 & NP & 146.1 \\
\hline & $11.0-27.0$ & $\mathrm{GC}$ & 19.0 & NP & 361.0 \\
\hline & $27.0-50.0$ & GW & 19.8 & NP & 838.9 \\
\hline \multirow{5}{*}{14} & $0.00-10.0$ & $\mathrm{GC}$ & 18.9 & NP & 140.0 \\
\hline & $10.0-16.0$ & GC & 18.9 & $\mathrm{NP}$ & 280.6 \\
\hline & $16.0-30.0$ & GC & 19.1 & NP & 507.8 \\
\hline & $30.0-36.0$ & $\mathrm{GC}$ & 19.6 & NP & 646.8 \\
\hline & $36.0-50.0$ & Tüf-Tüfit & 20.6 & 14 & 885.8 \\
\hline \multirow{3}{*}{18} & $0.00-29.0$ & $\mathrm{CL}$ & 17.0 & 11 & 214.3 \\
\hline & $29.0-43.0$ & GW & 20.4 & NP & 1183.6 \\
\hline & $43.0-50.0$ & $\mathrm{CL}$ & 17.2 & 13 & 560.1 \\
\hline \multirow{5}{*}{20} & $0.00-10.0$ & GM & 17.9 & NP & 134.4 \\
\hline & $10.0-15.0$ & GM & 18.2 & NP & 410.9 \\
\hline & $15.0-25.0$ & GM & 17.9 & NP & 393.8 \\
\hline & $25.0-45.0$ & Tüf-Tüfit & 20.4 & 5 & 1301.1 \\
\hline & $45.0-50.0$ & Tüf-Tüfit & 20.4 & 5 & 1833.4 \\
\hline \multirow{4}{*}{21} & $0.0-8.0$ & SM & 17.6 & $\mathrm{NP}$ & 141.2 \\
\hline & $8.0-21.5$ & SM & 17.6 & NP & 318.6 \\
\hline & $21.5-35.0$ & SM & 17.6 & NP & 515.0 \\
\hline & $35.0-50$ & GW & 19.8 & NP & 952.4 \\
\hline
\end{tabular}


Çözümlemelerden çalışma alanı için 1D Vs-derinlik modelleri oluşturulmuş ve bu veriler kuyu litolojileri ile korole edilmiştir. Şekil 5'te verilen 1 boyutlu hız modellerinden görüleceği üzere düşük-yüksek plastisiteli kil, silt ve kum içeren formasyonlarda hız değerleri hakim olarak 200-400 m/s aralığındadır (Şekil 5’ de S7, S10, S21). Ayrıca çakıl ve kumun derecelenmesine göre Vs'in yer yer $500 \mathrm{~m} / \mathrm{s}$ hız seviyesine kadar yükseldiği de gözlenmektedir (Şekil 5'de S8, S12). Son olarak kuyu litolojilerinde yer alan bir diğer birim olan tüf-tüfit (Şekil 5' de S7, S14, S20) ise yaklaşık 600 $\mathrm{m} / \mathrm{s}$ ve üzeri Vs hızları ile tanımlanmıştır. Çalışma alanın genelinde yüzeydeki hız dağılımı yaklaşık $200 \mathrm{~m} / \mathrm{s}$ ile $340 \mathrm{~m} / \mathrm{s}$ aralığında değişirken, derinlikle birlikte bu dağılım yaklaşık 400-900 m/s hız aralığına kadar yükselmiștir.

Öte yandan çalıșma alanında her veri kazanım noktasında mühendislik ana kayasına (Vs:760 m/s) ulaşılması mümkün olmamıştır. Hardin ve Drnevich (1972) Vs'in yüzeyden ana kayaya doğru gerilmenin üssel bir fonksiyonu olarak değişim gösterdiğini belirlemiş, Robertson vd. (1992) ise Vs'i gerilmeye göre normalize etmiştir (4).

$V s_{i}=V s\left(P a / \sigma_{v}^{\prime}\right)^{0.25}$

Verilen eşitlikte $P a$ atmosferik basıncı $(100 \mathrm{kPa}), V s$ kayma dalgası hızını, $V s_{i}$ normalize edilmiş kayma dalgası hızını, $\sigma_{v}^{\prime}$ ise düşey efektif gerilmeyi temsil etmektedir.

Mühendislik ana kayasına ulaşılan noktalarda Finn (1995), Ansa vd. (2004) ve Sönmezer vd. (2019) tarafından da belirtildiği gibi mevcut derinlik seviyesinin zemin parametreleri yeterli görülmüş çözümlemeler ilk 50 metredeki zemin parametreleri kullanılarak gerçekleştirilmiştir. Mühendislik ana kayasında ulaşılamayan noktalarda ise ZTA analizinde zemin tabakaları yarı sonsuz elastik ara yüzey sınırlandırılmıştır (Lee vd. 2006; Foerster ve Modaressi 2007; Hosseini ve Pajouh 2012; Hashash vd. 2017). Bu ara yüzeye ait veri ilk 50 metrenin kayma dalgası hızı kullanılarak (Sönmezer vd. 2019; Sönmezer ve Çeliker 2020) eşitlik (4) yardımı ile elde edilmiştir.

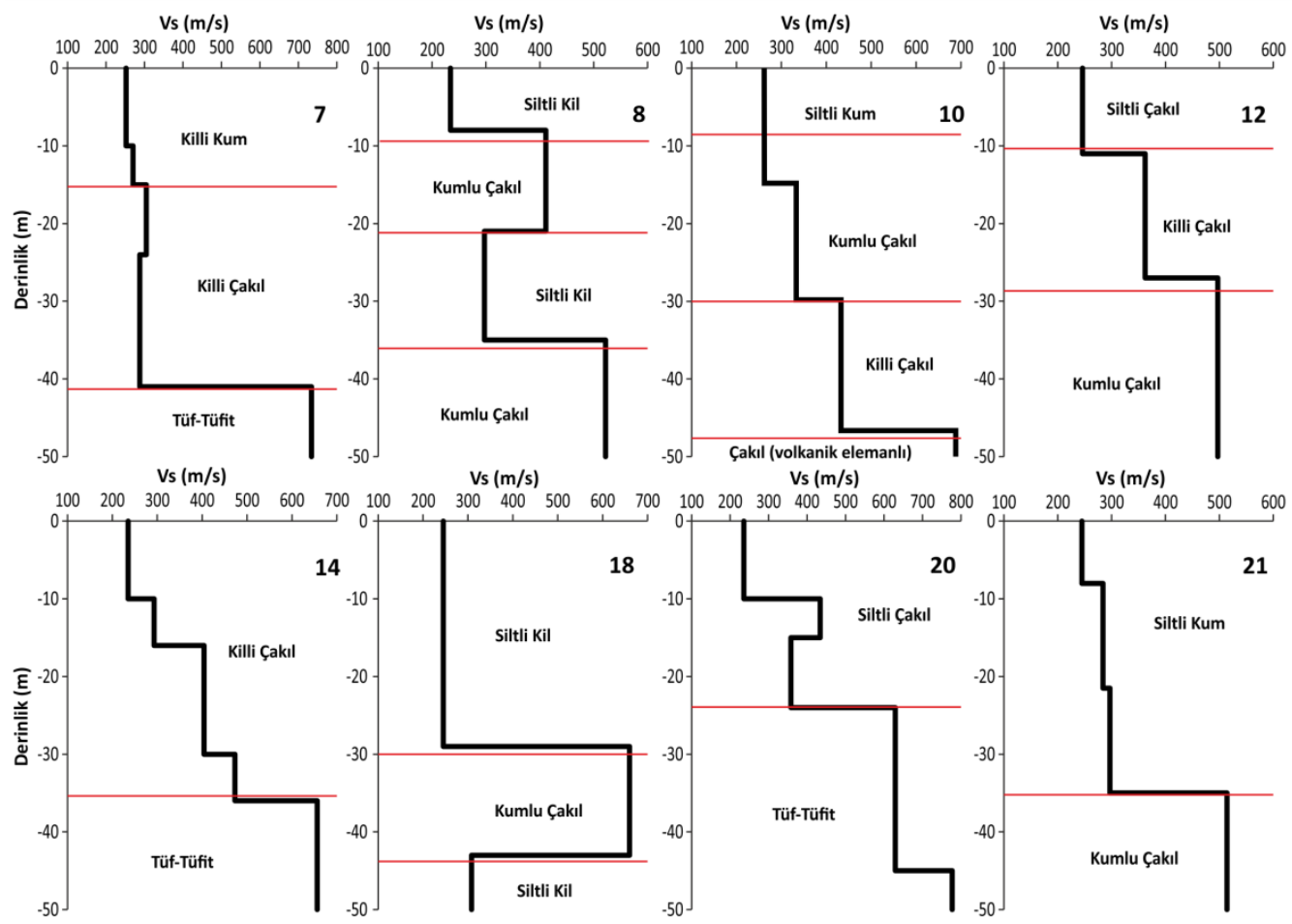

Şekil 5: Çalışma alanındaki bazı noktalardaki 1D derinlik-Vs hız kesitleri ve bu seviyelere karşılık gelen jeolojik birimler

\subsubsection{Temel zemin ve malzeme modeli}

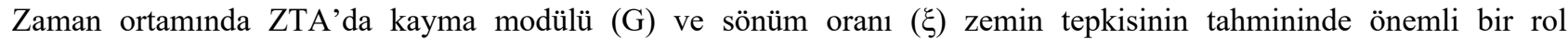
oynamaktadır. G ve $\xi$ döngüsel yükleme altında kayma gerilmesinin bir fonksiyonu olarak dikkate alınır. Deformasyon altındaki zemindeki değişim gerilme bağımlı kayma modülü azalım eğrisi $\left(\mathrm{G} / \mathrm{G}_{0}-\gamma\right)$ ve sönümleme eğrisi $(\xi-\gamma)$ ile belirlenir (Rayhani vd. 2008; Hashash vd. 2015; Sönmezer vd. 2019). Sahaya özgü döngüsel yükleme testlerin olmadı̆̆1 durumlarda $\mathrm{G} / \mathrm{G}_{0}-\gamma$ ve $\xi-\gamma$ eğrileri için geliştirilen ampirik standart eğriler alternatif olarak kullanılabilir (Kumar vd. 2014; Régnier vd. 2016). Çözümlemede kullanılan DEEPSOIL programında farklı zemin koşulları için bir dizi azalım ve sönümleme eğrisi tanımlanmıştır.

$\mathrm{Bu}$ çalışmada temel zemin modeli olarak genişletilmiş MKZ modeli, basınca bağlı hiperbolik model prosedürü (MRDF) ile kullanılmıştır. Bu prosedür genişletilmiş Masing histerik davranışını, azalım ve sönümleme eğrilerini, geniş bir kesme dayanımı aralığında eş zamanlı olarak karşılaştırır (Kaklamanos vd. 2015). 
Çalışmada alansal bazlı malzeme modeli, azalım ve sönümleme eğrilerinin seçiminde birçok çalışmada başarılı bir şekilde kullanılan; kumlu tabakalar için Darendeli (2001), kil-silt tabakalar için ise Vucetic ve Dobry (1991) eğrileri kullanılmıştır. Ayrıca çalışma alanında yer alan çakıl içeren formasyonların azalım ve sönümleme eğrilerinde Menq (2003), tüf-tüfit içerikli formasyonlarda ise Seed ve İdriss (1970-upper bound) eğrileri kullanılmıştır (Stokoe vd. 2006; Bajaj ve Andazgahan 2019). Bu doğrultuda çalışma alanı için oluşturulan tipik azalım ve sönüm oranı eğrileri Şekil 6 'da verilmiştir.
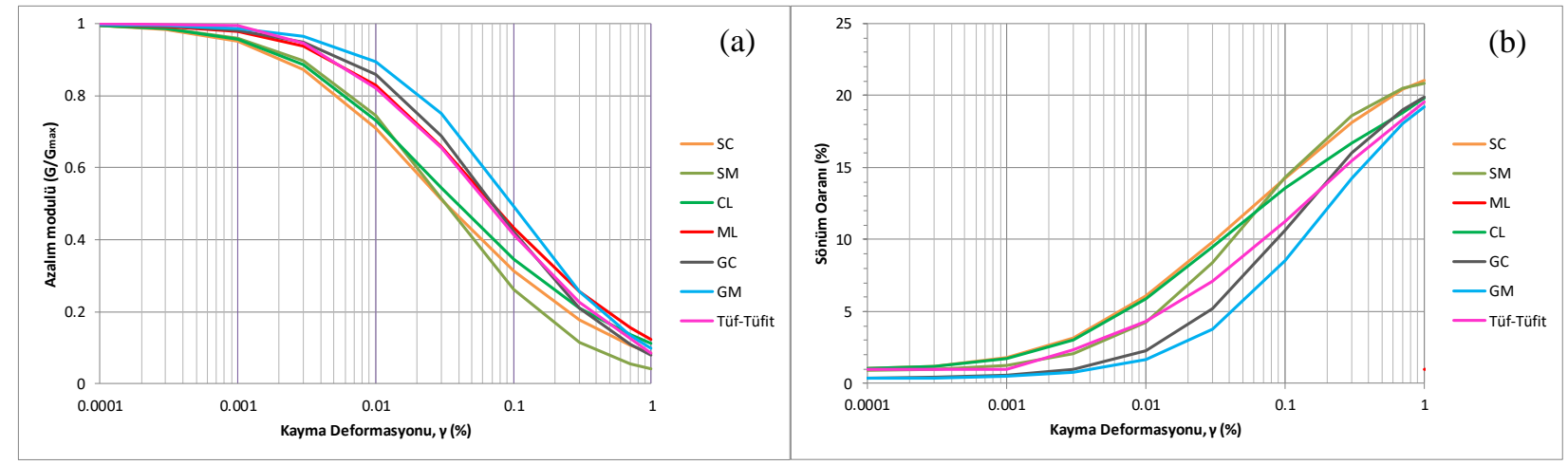

Şekil 6: Çalışma alanı tipik zemin modeli azalım (a) ve sönümleme (b) eğrileri

\subsubsection{Kuvvetli yer hareketi seçimi}

ZTA'da bir diğer önemli bileşen çalışma alanı ile uyumlu ivme kaydıdır. Daha önce ifade edildiği gibi tarihsel depremler de dikkate alındığında çalışma alanını üzerinde en etkili deprem FBFZ'nin 40 km'lik segmentinde meydana gelmiş normal faylanma mekanizmalı Ms 7.0 1914 Burdur depremidir. Bu nedenle çalışma kapsamında bu depremin senaryosu planlanmıştır. Ancak tarihsel dönemde meydana gelen bu depremin kuvvetli yer hareketi kaydı bulunmamaktadır. Ne yazık ki ulusal kuvvetli yer hareketi ağında bu büyüklükte normal faylanma mekanizmalı kuvvetli yer hareketi kaydı da bulunmamaktadır. Işık (2010) benzer problemi İtalya ivme veri tabanından (İTACA) sağladığı ivme kaydı ile çözümlemiştir. Bu nedenle bu çalışmada 1914 depreminin modellenmesinde İTACA veri tabanından elde edilen normal faylanma mekanizmal1 1980 Irpinia depreminin (Mw:6.9) Sturno-Irpinia istasyonu kaydı SeismoMatch programı vasıtasıyla çalışma alanı zemin koşullarına indirgeme yapılarak kullanılmıştır (Şekil 7). Kuvvetli yer hareketinin maksimum ivme değeri $0.22 \mathrm{~g}$ iken, en yüksek spektal ivme 0.3-0.4 s periyodu aralığında 0.9 g'dir.
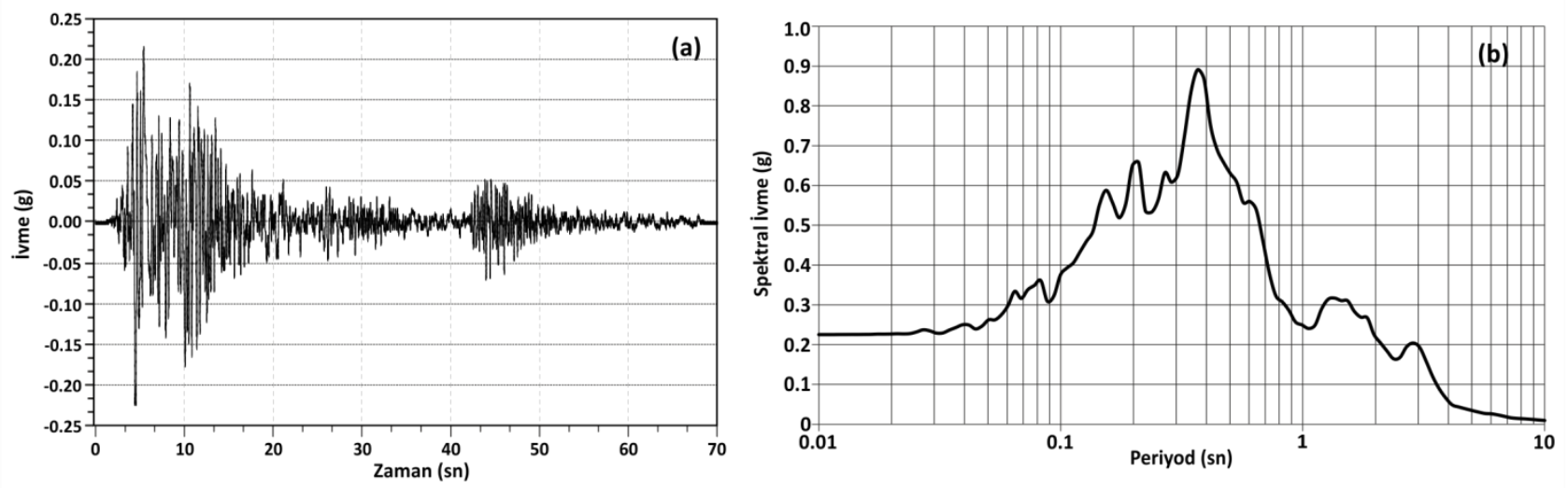

Şekil 7: Zemin tepki analizinde kullanılan ivme kaydı (a) ve \%5 sönümlü tepki spektrumu (b)

\section{Bulgular ve Sonuçlar}

Isparta şehir merkezi ve yakın çevresini kapsayan 24 noktada 1D doğrusal olmayan ZTA değerleri elde edilmiştir. Doğrusal olmayan zemin tepki analizinde ise birçok çalışmada başarılı bir şekilde kullanılan DEEPSOİL programı (Hashash vd. 2017) kullanılmıştır. 1D Vs-derinlik modelleri kullanılarak veri kazanım noktalarında Vs $s_{30}$ hesaplanarak zemin sınıflaması yapılmıştır. Sondaj ve ReMi verilerinden elde edilen dinamik zemin parametreleri DEEPSOIL' e aktarılarak her bir veri kazanım noktasındaki Pga ve maksimum Sa değerleri elde edilmiştir. 
Çalışma alanının geneline dair yorum yapabilmek adına en yakın komşu algoritması (nearest neighbor) ile noktalar arası interpole edilerek maksimum Pga ve Sa dağılım haritası hazırlanmıştır. Son olarak havza içerisinde birbirine dik iki profil üzerinde Pga ve $\mathrm{Vs}_{30}$ uyumu karşıllaştırılmıştır.

Daha önce değinildiği üzere ilk 30 metredeki tabakalaşma zemin tepkisini belirlemede son derece önemli bir bilgidir. Zemin tepkisini azaltmada veya arttırmada etkili ilk 30 metrenin ortalama kayma dalgası hızı (Vs30) eşitlik (5) vasıtasıyla ReMi 1D hız profillerinden (Şekil 4) hesaplanmıştır.

$V s^{*}=\frac{30}{\sum_{\mathrm{i}=1}^{\mathrm{n}} \frac{\mathrm{h}_{\mathrm{i}}}{\mathrm{V}_{\mathrm{i}}}}$

Burada; $h_{i}$ tabaka kalınlığını, $V_{i}$ ise $h_{i}$ kalınlığındaki tabakanın kayma dalgası hızıdır. Havza içerisinde Vs $s_{30}$ değerleri en yüksek yoğunluklu olarak $360 \mathrm{~m} / \mathrm{s}$ hız ile sınırlı kalmakla birlikte en düşük $283 \mathrm{~m} / \mathrm{s}$ aralığında ortaya çıkmaktadır. 12 numaralı veri kazanım noktasında $\mathrm{Vs}_{30}$ değeri göreceli olarak sınırlı bir şekilde $(\sim 380)$ bu eşiğin üzerinde çıkmıştır. Havza sınırında ise $\mathrm{Vs}_{30}$ değerleri $480 \mathrm{~m} / \mathrm{s}$ hıza kadar atış göstermektedir (Şekil 8).

Kayma dalgası hızı $\left(\mathrm{Vs}_{30}\right)$ ile zemin özelliklerinin belirlenmesinde çeşitli zemin sınıflama kriterleri kullanılmaktadır. Bu çalışmada Vs 30 verisini dikkate alarak sınıflama yapan TBDY-2018 kriterleri kullanılmıştır. Bu kriterler Tablo 2' de özetlenmiştir. TBDY-2018'e göre yapılan sınıflama neticesinde havza içi ZD zemin grubu ile tanımlanırken, havza kenarları ZC zemin grubu ile tanımlanmıştır (Şekil 8).

Tablo 2: TBDY-2018 zemin sınıflama kriterleri

\begin{tabular}{ccc}
\hline TBDY-2018 & Zemin Tanımı & $\begin{array}{c}\text { Vs30 } \\
(\mathrm{m} / \mathrm{s})\end{array}$ \\
Zemin Sınıf & & $>1500$ \\
ZA & Sert kaya & $760-1500$ \\
ZB & Kaya & $360-760$ \\
ZC & Çok sert veya sert zemin & $180-360$ \\
ZD & Sert zemin & $<180$ \\
ZE & Yumuşak zemin & \\
\hline
\end{tabular}

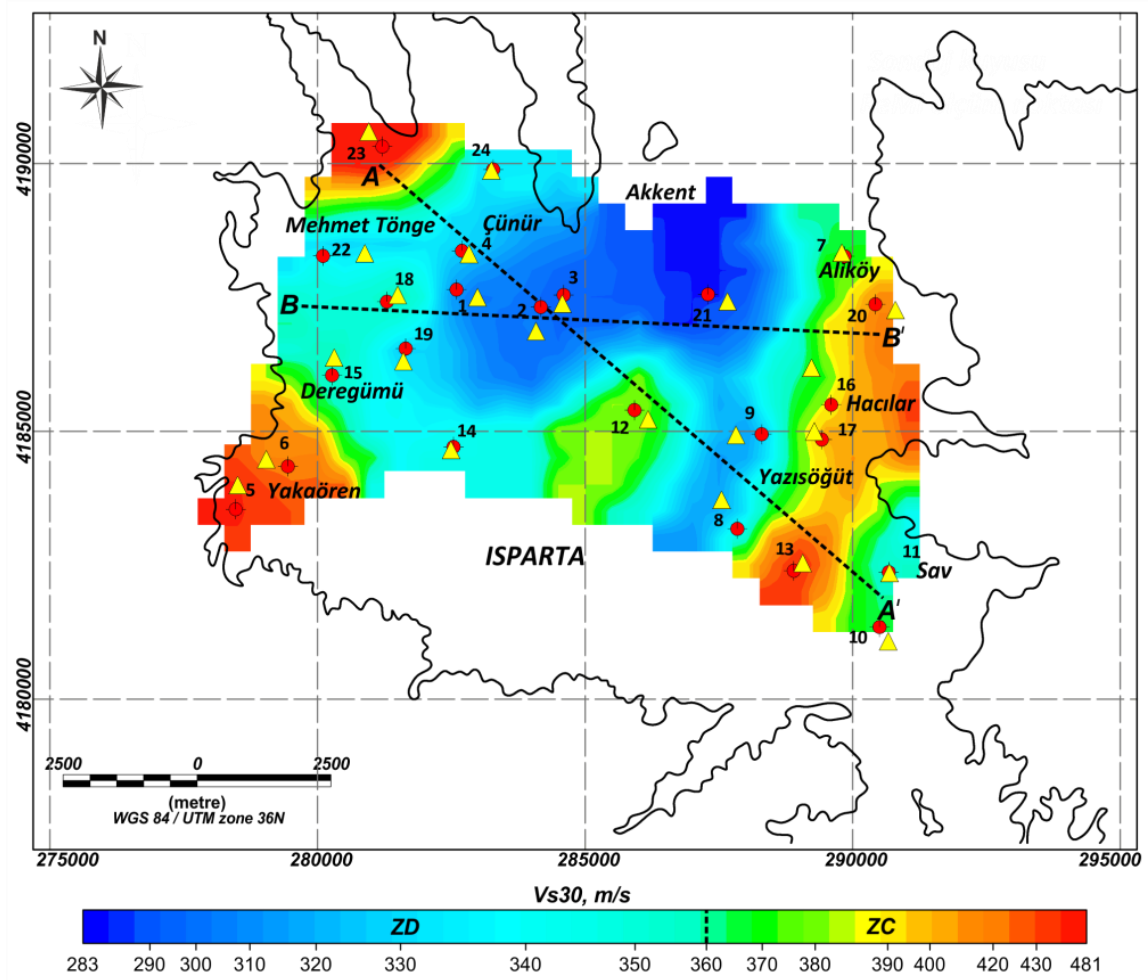

Şekil 8: Havzadaki Vsso dağııımı (Haritada sarı üçgenler ReMi veri kazanım noktalarını, kırmızı noktalar sondaj ıokasyonlarını göstermektedir)

Dinamik zemin parametreleri kullanılarak yapılan çözümlemelerde havzadaki en büyük ivme değerleri 0.25-0.42 g aralığında değişmektedir (Tablo 3). Bu Pga değerlerinin bir kısmı Türkiye deprem tehlikeleri haritasında çalışma alanı için belirtilen $0.3 \mathrm{~g}$ Pga değerinin üzerinde yer almaktadır. 
Ortaya çıkan bu durum yerel zemin koşulları etkisinin bu haritaların hazırlanmasında genel çerçeve dikkate alınarak hazırlandığını göstermektedir. Bir diğer önemli parametre olan \%5 sönümlü tek serbestlik dereceli sistemlerin maksimum ivme davranış spektrumları (Sa) 0.77-1.94 g aralığında değişim göstermektedir (Tablo 3).

Tablo 3: Çalışma kapsamında ZTA' dan elde edilen sonuçlar

\begin{tabular}{|c|c|c|c|c|}
\hline $\begin{array}{l}\text { Ölçüm } \\
\text { No }\end{array}$ & PGA (g) & $\begin{array}{l}\text { \%5 Sönümlü } \\
\text { mak. SA (g) }\end{array}$ & $\begin{array}{l}V_{\mathrm{s} 30} \\
(\mathrm{~m} / \mathrm{s}) \\
\end{array}$ & $\begin{array}{c}\text { TBEC } \\
2018 \\
\end{array}$ \\
\hline 1 & 0.334 & 1.04 & 284 & ZD \\
\hline 2 & 0.358 & 1.35 & 308 & ZD \\
\hline 3 & 0.332 & 1.43 & 290 & ZD \\
\hline 4 & 0.408 & 1.82 & 337 & ZD \\
\hline 5 & 0.366 & 1.22 & 452 & $\mathrm{ZC}$ \\
\hline 6 & 0.412 & 1.94 & 407 & $\mathrm{ZC}$ \\
\hline 7 & 0.252 & 0.77 & 361 & $\mathrm{ZC}$ \\
\hline 8 & 0.311 & 0.94 & 312 & ZD \\
\hline 9 & 0.324 & 1.06 & 297 & ZD \\
\hline 10 & 0.337 & 1.28 & 357 & ZD \\
\hline 11 & 0.334 & 1.21 & 342 & ZD \\
\hline 12 & 0.377 & 1.12 & 384 & $\mathrm{ZC}$ \\
\hline 13 & 0.340 & 1.36 & 458 & $\mathrm{ZC}$ \\
\hline 14 & 0.420 & 1.74 & 344 & $\mathrm{ZD}$ \\
\hline 15 & 0.327 & 1.05 & 360 & $\mathrm{ZC}$ \\
\hline 16 & 0.346 & 1.05 & 358 & ZD \\
\hline 17 & 0.360 & 1.23 & 421 & $\mathrm{ZC}$ \\
\hline 18 & 0.262 & 0.86 & 386 & $\mathrm{ZC}$ \\
\hline 19 & 0.400 & 1.59 & 314 & ZD \\
\hline 20 & 0.420 & 1.82 & 441 & $\mathrm{ZC}$ \\
\hline 21 & 0.295 & 0.92 & 283 & ZD \\
\hline 22 & 0.343 & 1.22 & 313 & ZD \\
\hline 23 & 0.278 & 1.02 & 481 & $\mathrm{ZC}$ \\
\hline 24 & 0.323 & 1.11 & 334 & ZD \\
\hline
\end{tabular}

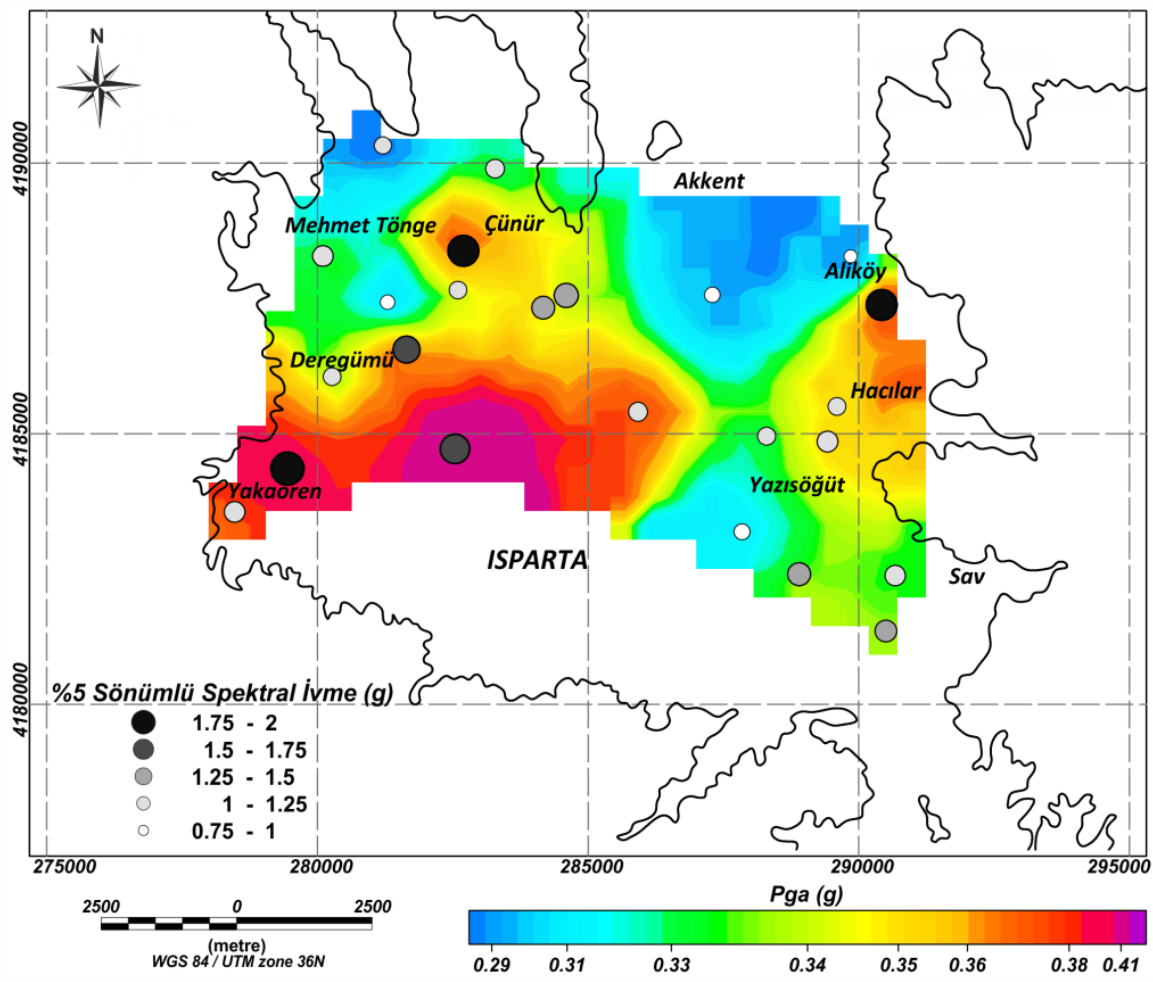

Şekil 9: Çalışma alanının yüzeydeki en büyük yer ivmesi (Pga) ve maksimum spektral ivme (Sa) dağıımı 
Zemin tepki analizinde elde edilen Pga ve Sa değerlerinin havza içerisindeki dağılımı Şekil 9'da verilmiştir. Haritada seçilen kuvvetli yer hareketi için en yüksek Pga değerlerinin gelişmesi beklenen alanlar belirlenmiştir. En yüksek Pga değerlerinin şehir merkezi, Deregümü, Yakaören ve Aliköy civarında meydana gelmesi beklenmektedir ve bu değerler ortalama $0.4 \mathrm{~g}$ seviyesindedir. Bu lokasyonlarda $\% 5$ sönümlü tek serbestlik dereceli sistemlerin maksimum ivme dağılımı incelendiğinde yaklaşık 1.0-1.94 g aralığında Pga sonuçları ile uyumlu oldukça yüksek Sa dağılımı söz konusudur. Pga seviyesinin yüksek olduğu bir diğer kısım S1, S2, S3 ve S4 ile çevrelenmiş (Şekil 8) Çünür köyüdür. Yeni yapılaşma projeleri ile öne çıkan bu alanda ise Pga değeri ortalama $0.35 \mathrm{~g}$, maksimum Sa ise $1 \mathrm{~g}$ civarındadır. S23'ün bulunduğu Süleyman Demirel Üniversitesi (Sdü) kampüs, Akkent, Yazısöğüt ve Mehmet Tönge'nin etrafindaki bölgeler ortalama 0.3 g Pga ve 0.75-1 g maksimum Sa değerleri ile nispeten daha düşüktür. Ancak Sa değerleri yapı periyotlarının bilinmesi ile daha anlamlıdır (Sönmezer vd. 2015). Bu bağlamada ampirik olarak bina hakim titreşim periyotları TBDY-2018'e göre aşağıdaki eşitlikten (6) hesaplanabilir.

$\mathrm{T}_{1}=C_{t} H_{N}^{0.75}$

Verilen eşitlikte $\mathrm{H}_{\mathrm{N}}$ bina yüksekliğini, $\mathrm{C}_{\mathrm{t}}$ titreşim katsayısını ifade etmektedir. Bina hakim titreşim periyodu için yapılan hesaplamada bina yüksekliği kat başına $3 \mathrm{~m}$ kabul edilebilirken, $\mathrm{C}_{\mathrm{t}}$ yönetmelikte belirtildiği gibi 0.07 olarak alınabilir. Çalışma alanında son 5-7 yıla kadar 3-6 kat arası betonarme yapı stoğu yaygınken, yeni yapılaşma alanlarında kat sayısı 8-12 aralığına yükselmiştir. Yapılan hesaplama neticesinde 3-6 kat aralığında bina periyotları 0.36-0.6 s, 8-12 kat aralığında ise 0.75-1.03 s aralığında değişim göstermektedir. Öte yandan Şekil 9 üzerinden de görüleceği üzere bu alanlarda Sa değerleri 1.5-2 g aralığında değişim göstermektedir. Bu bilgiler yüksek pga (0.4 g) değerlerine sahip şehir merkezi, Deregümü, Yakaören ve Aliköy gibi alanlarda 8-12 katlı binaların ciddi deprem yükü etkisine maruz kalabileceğini göstermektedir. Benzer şekilde yeni yapılaşma alanlarının yoğunlaştı̆ğ Çünür bölümünde de 8-12 katlı yapıların yüksek sismik yüklemeye maruz kalabileceği anlaşılmaktadır. Ayrıca bölge genelinde Sa değerleri 1 g'nin üzerinde dağılım göstermektedir. Çalışma alanında yaygın yapı stoğunun salınım periyotlarının $0.36-0.6 \mathrm{~s}$ aralığında değişim göstermesi dikkate alındığında sismik tehlike açısından çalışma alanın önemli bir bölümü risk içermektedir. Tüm bunların yanında sismik tehlike riski üzerinde depremin süresi ve frekans içeriğinin de önemli bir etken olduğu unutulmamalıdır.
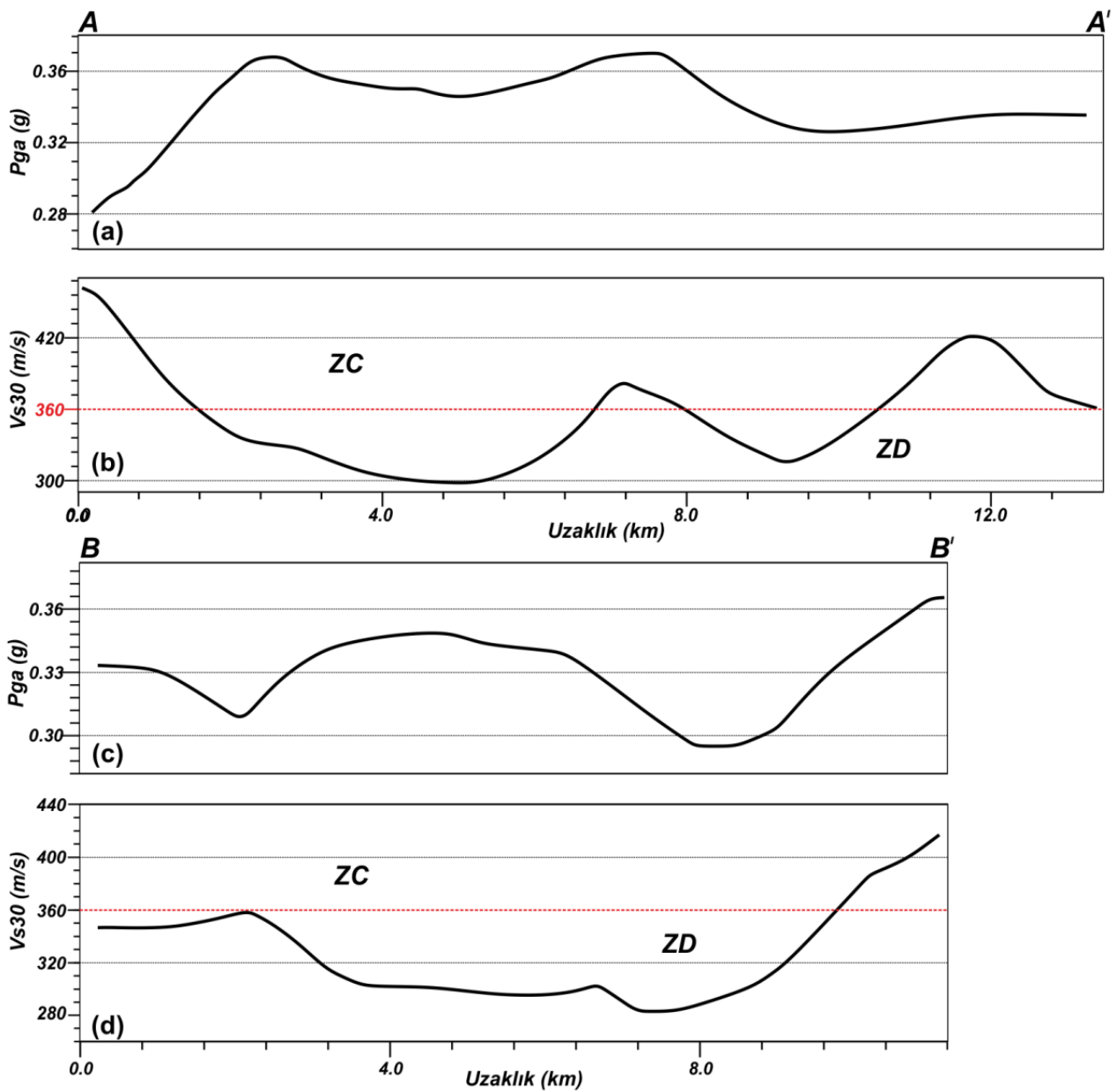

Şekil 10: $A A^{\prime}$ ve $B B^{\prime}$ profilleri boyunca alınan en kesit Pga ve Vsзo kesitleri 
Son olarak yerel zemin koşulları ile Pga değerleri arasındaki değişimi inceleyebilmek adına havza içerisinde birbirine yaklaşık dik iki profil üzerinde (Şekil 8) karşılaştırma yapılmıştır (Şekil 10). Yaklaşık K-G yönünde alınan A-A' kesitinde $\mathrm{Vs}_{30}$ değerleri havza kenarları dışında ZD-ZC sınırı olan $360 \mathrm{~m} / \mathrm{s}$ hızın altındadır (Şekil 10b). Buna karşılık Şekil 10a'da Pga değerleri genel olarak 0.3 g’nin üzerindedir. Vs ${ }_{30}$ hızının yükseldiği yerde beklendiği gibi Pga değerlerinde göreceli bir düşüş gözlenmektedir. $360 \mathrm{~m} / \mathrm{s}$ hız değerinin altında ZD zemin grubu ile tanımlanan kısımlarda Pga değerleri 0.3 g'nin üzerindedir. D-B yönlü B-B' Pga kesitinde (Şekil 10c) en büyük yer ivmesi değerleri 0.3-0.36 g aralığında değişim göstermektedir. Pga değerleri kesit boyunca zeminin dinamik özelliklerine bağlı salınım trendi göstermekle birlikte, bu trend Şekil 10d'de verilen Vs $s_{30}$ eğrisi ile benzerdir. Ancak kesitin yaklaşık 10. km'sinde $\mathrm{Vs}_{30}$ hızı artmasına karşın PGA değerinde dikkate değer bir azalım söz konusu değildir. Basu ve Dey (2016) Vs-derinlik ve Pga arasındaki korelasyonu inceledikleri çalışmada sabit kayma dalgası ve yoğunluk kullanarak PGA değerlerinin düşük hız aralığında (200-400 m/s) yükselebileceğini ifade etmiştir. Öte yandan çalışmada yüzeydeki PGA dağılımı irdelenmiş olması nedeni ile $30 \mathrm{~m}$ derinliğinin ortalama hızı eğrisi ile birebir aynı olması beklenmez. Şekil 5'de verilen 1D hız modellerinde 20 numaralı sondaj kesiti bu durumu açıkça göstermektedir. Veri kazanım lokasyonunda yüzeydeki Vs değeri yaklaşık $230 \mathrm{~m} / \mathrm{s}$ olmasına karşın $\mathrm{Vs}_{30}$ değeri $441 \mathrm{~m} / \mathrm{s}$ (Tablo 3) saniyedir. Bu bakımdan A-A' ve B-B' kesitleri de dikkate alındığında elde edilen Pga ve $\mathrm{Vs}_{30}$ haritaları temel çerçevede birbirleriyle uyumludur.

\section{Tartışma ve Öneriler}

$\mathrm{Bu}$ araştırmada, Isparta şehir merkezi ve yakın çevresini kapsayan alanda zemine ait 1 boyutlu doğrusal olmayan ZTA (zaman ortamında) değerleri hesaplanmıştır. 1 boyutlu ZTA analizi bölgedeki depremsellik dikkate alınarak çalışma alanı üzerinde en etkili 1914 Burdur depremi için senaryolandırılmıştır. Tarihsel döneme ait bu senaryo deprem modelinde kuvvetli yer hareketi, benzer zemin özelliklerini ihtiva eden 1980 Irpinia depreminin (Mw:6.9) SturnoIrpinia istasyonu kaydı ile gerçekleştirilmiştir. Senaryo deprem ZTA modellemesinde zemin parametresi değişkenleri toplamda 24 noktada elde edilen sismik ve sondaj verilerinden hesaplanmıştır. Sondaj ve sismik (ReMi) verilerinden elde edilen dinamik parametreler DEEPSOIL programında Sa ve Pga hesaplamaları için kullanılmıştır. Çalışma alanının farklı lokasyonundaki zemin tepkilerine dair bir fikir vermesi için Sa ve Pga dağılım haritaları düzenlenmiştir. Yüzeydeki maksimum Pga dağılımının 0.25-0.42 g aralığında değişim gösterdiği ve bu değerlerin bir kısmının Türkiye deprem tehlikeleri haritasında çalışma alanı için belirtilen en büyük yer ivmesi değerinden $(0.3 \mathrm{~g})$ yüksek olduğu gözlenmiştir. Çalışma alanındaki maksimum Sa ise 0.77-1.94 $\mathrm{g}$ aralığında değişim göstermektedir. Havza içerisinde en yüksek Pga değerleri bu değerler ile uyumlu Sa değerleri şehir merkezi, Deregümü, Yakaören ve Aliköy civarında elde edilmiştir. Yüksek Sa değerlerinin çalışma alanındaki yapı stoğu periyodu ile anlamlandırabilmek adına amprik hesaplama yapılmış ve yoğunluklu olarak 3-6 ve 8-12 (Çünür gibi yeni yerleşim yerleri) kat yapı stoğu ihtiva eden çalışma alanındaki bina periyotları 3-6 kat için 0.36-0.6 s, 8-12 kat için ise 0.75-1.03 s olarak hesaplanmıştır. Buradan elde edilen bina periyotları da dikkate alındığında doğrusal olmayan 1D ZTA analizinden havzanın büyük bir bölümünün yüksek tehlike arz ettiği vurgulanmıştır. $V_{s_{30}}$ dağılımının $280-480 \mathrm{~m} / \mathrm{s}$ aralığında değişim gösterdiği çalışma alanında alüvyal istifin hakim olduğu havza içinde $\mathrm{Vs}_{30}$ değerlerinin $\mathrm{ZC}$ zemin sınırı eşik değeri olan $360 \mathrm{~m} / \mathrm{s}$ ile sınırlı kaldığı, havza kenarlarında ise hızların $480 \mathrm{~m} / \mathrm{s}$ ' ye kadar göreceli yükseldiği tespit edilmiştir. TBDY-2018 zemin sınıflama kriterlerine göre havza ZC ve ZD zemin grubu ile tanımlanmıştır. Ayrıca yerel zemin koşulları ile Pga değerleri arasındaki ilişkiyi inceleyebilmek adına havza içerisinde iki profilde üzerinde yapılan değerlendirmede Pga'nın $\mathrm{Vs}_{30}$ ile oldukça uyumlu olduğu ortaya çıkmıştır.

Sonuçlar, deprem güvenli dayanıklı yapı tasarımında yerel zemin koşullarının önemine dikkat çekmektedir. Özellikle deprem tehlikesinin bu denli yüksek olduğu şehir merkezlerinde, bölge özelinde bu şekilde genel çalışmalar yapılsa da tasarım yapılmadan önce mutlaka lokal ölçekte sahaya özel çalışmaların yapılması gerekmektedir. Bu çalışma sonuçlarından da görüldüğü gibi birbirine yakın mesafede veri kazanım noktalarında yapılmış ZTA analizlerinin sonuçları, yerel zemin koşullarının etkisinin gösterdiği farklılığı açıkça gözler önüne sermektedir. Bu durum özellikle çalışma alanında birbirine çok yakın konumlu Mehmet Tönge ile Çünür arasında oldukça belirgindir.

$\mathrm{Bu}$ çalışmada elde edilen parametreler, özellikle şehir merkezinin kuzey bölümünde yeni yapılaşma alanı Çünür ve çevresinde sismik yapı tasarımına önemli katkılar sağlayabilir. Ayrıca şehrin yüksek Pga değerlerinin beklendiği bölümlerinde yeni yapıların tasarımına özel önem verilmelidir. Diğer taraftan havzadaki mevcut yapı stoğunun da hasar görebilirlik riskini en aza indirgemede çalışma sonuçlarının dikkate alınması önerilir.

\section{Kaynaklar}

Akbulut A., (1980), Eğirdir Gölü güneyinde Çandır (Sütçüler-Isparta) yöresindeki Batı Torosların jeolojisi, Geological Bulletin of Turkey, 23(1), 1-9.

Akın M.K., Kramer, S.L., Topal, T., (2016), Dynamic soil characterization and site response estimation for Erbaa, Tokat (Turkey, Natural Hazards, 82(3), 1833-1868.

Ansa A., Biro Y., Erken A., Gülerce Ü., (2004), Seismic microzonation: a case study. In Recent advances in earthquake geotechnical engineering and microzonation, Springer, Dordrecht, ss.253-266.

Ansal A.M., İyisan R., Güllü H., (2001), Microtremor measurements for the microzonation of Dinar, Pure and Applied Geophysics, 158, 2525-2541. 
Arslan H., Siyahi B., (2006), A comparative study on linear and nonlinear site response analysis, Environmental geology, 50(8), 1193-1200.

Assimaki D., Kausel E., Whittle A., (2000), Model for dynamic shear modulus and damping for granular soils, Journal of Geotechnical and Geoenvironmental Engineering, 126(10), 859-869.

Bajaj K., Anbazhagan P., (2019), Identification of shear modulus reduction and damping curve for deep and shallow sites: kik-net data, Journal of Earthquake Engineering, doi: 10.1080/13632469.2019.1643807.

Basu D., Dey A., (2016), Comparative 1D ground response analysis of homogeneous sandy stratum using Linear, Equivalent Linear and Nonlinear Masing approaches, Geotechnics for Infrastructure Development, Indian Geotechnical Society, West Bengal, India, ss.1-7.

Basu D., Boga M., Dey A., (2019), A time-domain nonlinear effective-stress non-Masing approach of ground response analysis of Guwahati city, India, Earthquake Engineering and Engineering Vibration, 18(1), 61-75.

Blumenthal M.M., (1963), Le systeme structural du Taurus sud Anatolies, Bull Soc Geol Fr In: Livre a Memoire de Professor P. Fallot. Mem Soc Geol Fr, 1(2), 611-662.

Borcherdt R.D., (1994), Estimates of site-dependent response spectra for design (methodology and justification), Earthquake spectra, 10, 617-617.

Bolisetti C., Whittaker A.S., Mason H.B., Almufti I., Willford M., (2014), Equivalent linear and nonlinear site response analysis for design and risk assessment of safety-related nuclear structures, Nuclear Engineering and Design, 275, 107-121.

Coburn A.W., Spence R.J., (2002), Earthquake protection, John Wiley and Sons, Chichester, England, 436ss.

Darendeli M.B., (2001), Development of a new family of normalized modulus reduction and material damping curves, PhD Thesis, Civil Engineering, Faculty of the Graduate School of The University of Texas at Austin, Texas, USA.

Finn W.D.L., (1995), Ventura CE Challenging issues in local microzonation. In: Proceedings of the 5th International Conference on Seismic Zonation, October 17-19, Nice, France.

Foerster E., Modaressi H., (2007), Nonlinear numerical method for earthquake site response analysis II—case studies, Bulletin of Earthquake Engineering, 5(3), 325-345.

Gautam D., Forte G., Rodrigues H., (2016), Site effects and associated structural damage analysis in Kathmandu Valley, Nepal, Earthquakes and Structures, 10(5), 1013-1032.

Goto H., Sawada S., Morikawa H., Kiku H., Özalaybey S., (2005), Modeling of 3D subsurface structure and numerical simulation of strong ground motion in the Adapazari basin during the 1999 Kocaeli earthquake, Turkey, Bulletin of the Seismological Society of America, 95(6), 2197-2215.

Görmüş M., Özkul M., (1995), Gönen-Atabey (Isparta) ve Ağlasun (Burdur) Arasındaki Bölgenin Stratigrafisi, Süleyman Demirel University Journal of Natural and Applied Sciences, 1, 43-64.

Görmüș M., Çoban H., Caran Ș., Uysal K., Bircan C., Tunç İ.O., (2005), Eğirdir Gölü Batısı Pliyo-Kuvaterner Sedimanları, Türkiye Kuvaterner Sempozyumu, 2-5 Haziran, İstanbul, ss.205-218.

Hardin B.O., Drnevich V.P., (1972), Shear modulus and damping in soils: design equations and curves, Journal of the Soil mechanics and Foundations Division, 98(7), 667-692.

Hasal M.E., İyisan R., (2014), A numerical study on comparison of $1 D$ and $2 D$ seismic responses of a basin in Turkey, American Journal of Civil Engineering, 2(5), 123-133.

Hashash Y.M., Park D., (2001), Non-linear one-dimensional seismic ground motion propagation in the Mississippi embayment, Engineering Geology, 62(1-3), 185-206.

Hashash Y.M., Phillips C., Groholski D.R., (2010), Recent advances in non-linear site response analysis, In: Proceedings of the fifth international conference on recent advances in geotechnical earthquake engineering and soil Dynamics, San Diego, California, ss.1-22.

Hashash Y.M., Dashti S., Romero M.I., Ghayoomi M., Musgrove M., (2015), Evaluation of 1-D seismic site response modeling of sand using centrifuge experiments, Soil Dynamics and Earthquake Engineering, 78, 19-31.

Hashash Y.M.A., Musgrove M.I., Harmon J.A., Ilhan O., Groholski D.R., Phillips C.A., Park D., (2017), DEEPSOIL 7.0, User Manual.

Hosseini S.M.M.M., Pajouh M.A., (2012), Comparative study on the equivalent linear and the fully nonlinear site response analysis approaches. Arabian Journal of Geosciences, 5(4), 587-597.

Işı N.S., (2010), Assessment of the site amplifications and predominant site periods for Saruhanl, in an earthquake-prone region of Turkey, Bulletin of engineering geology and the environment, 69(2), 309-319.

Kaklamanos J., Baise L.G., Thompson E.M., Dorfmann L., (2015), Comparison of 1D linear, equivalent-linear, and nonlinear site response models at six KiK-net validation sites, Soil Dynamics and Earthquake Engineering, 69, 207-219.

Kanlı A.İ., Tildy P., Prónay Z., Pınar A., Hermann L., (2006), Vs30 mapping and soil classification for seismic site effect evaluation in Dinar region, SW Turkey, Geophysical Journal International, 165(1), 223-235.

Karaman M.E., Meriç E., Tansel İ., (1988), Çünür (Isparta) dolaylarında Kretase-Tersiyer geçişi, Akdeniz Üniversitesi Isparta Mühendislik Fakültesi Dergisi, 4, 80-100.

Kazanc1 N., Karaman M.E., (1988), Gölcük (Isparta) Pliyosen volkanoklastiklerinin sedimenter özellikleri ve depolanma mekanızmaları, Akdeniz Üniversitesi Isparta Mühendislik Fakültesi Dergisi, 4, 16-35.

Kazanc1 N., (1990), Fan-delta sequences in the Pleistocene and Holocene Burdur Basin, Turkey: the role of basin-margin configuration in sediment entrapment and differential facies development, Coarse-grained Deltas'in İçinde (Colella A, Prior D.B. Ed.), Wiley, ss.185-198.

Khanbabazadeh H., İyisan R., Ansal A., Hasal M.E., (2016), 2D non-linear seismic response of the Dinar basin, TURKEY, Soil Dynamics and Earthquake Engineering, 89, 5-11.

Koçyiğit A., Özacar A.A., (2003), Extensional neotectonic regime through the NE edge of the Outer Isparta Angle, SW Turkey: new field and seismic data, Turkish Journal of Earth Sciences, 12(1), 67-90.

Kramer S.L., (1996), Geotechnical earthquake engineering, In prentice-Hall international series in civil engineering and engineering mechanics, Prentice-Hall, New Jersey, 273ss. 
Kumar S.S., Krishna A.M., Dey A., (2014), Nonlinear site-specific ground response analysis: case study of Amingaon, Guwahati, In: 15th symposium on earthquake engineering, December 11-13, IIT Roorke, India, ss.308-318.

Kwok A.O., Stewart J.P., Hashash Y.M., Matasovic N., Pyke R., Wang Z., Yang Z., (2007), Use of exact solutions of wave propagation problems to guide implementation of nonlinear seismic ground response analysis procedures, Journal of Geotechnical and Geoenvironmental Engineering, 133(11), 1385-1398.

Lee C.P., Tsai Y.B., Wen K.L., (2006), Analysis of nonlinear site response using the LSST downhole accelerometer array data, Soil Dynamics and Earthquake Engineering, 26(5), 435-460.

Louie J.N., (2001), Faster, better: shear-wave velocity to 100 meters depth from refraction microtremor arrays, Bulletin of the Seismological Society of America, 91(2), 347-364.

Louie J.N., Pancha A., Pullammanappallil S., (2017), Applications of Refraction Microtremor Done Right, and Pitfalls of Microtremor Arrays Done Wrong, 16th World Conference on Earthquake Engineering, Santiago Chile, Paper No: 4947.

Matasovic N., (1993), Seismic response of composite horizontally-layered soil deposits, PhD Thesis, Department of civil engineering, University of California at Los Angeles, USA.

Menq F.Y., (2003), Dynamic properties of sandy and gravelly soils, PhD Thesis, Department of Civil Engineering, University of Texas, Austin, USA.

Özel O., Sasatani T., (2004), A site effect study of the Adapazari basin, Turkey, from strong and weak-motion data, J Seismol 8(4), 559-572.

Park D., Hashash Y.M., (2008), Rate-dependent soil behavior in seismic site response analysis, Canadian Geotechnical Journal, 45(4), 454-469.

Phillips C., Hashash Y.M., (2009), Damping formulation for nonlinear 1D site response analyses, Soil Dynam Earthq Eng, 29(7), 1143-58.

Poisson A., Yağmurlu F., Bozcu M., Şentürk M., (2003), New insights on the tectonic setting and evolution around the apex of the Isparta Angle (SW Turkey), Geological Journal, 38(3-4), 257-282.

Rayhani M.H.T., El Naggar M.H., Tabatabaei S.H., (2008), Nonlinear analysis of local site effects on seismic ground response in the Bam earthquak, Geotechnical and Geological Engineering, 26(1), 91-100.

Régnier J., Bonilla L.F., Bard P.Y., Bertrand E. et al., (2016), International benchmark on numerical simulations for 1D, nonlinear site response (PRENOLIN): Verification phase based on canonical cases, Bulletin of the Seismological Society of America, 106(5), 2112-2135.

Régnier J., Bonilla L.F., Bard P.Y., Bertrand E. et al., (2018), PRENOLIN: International Benchmark on 1D Nonlinear Site-Response Analysis-Validation Phase ExercisePRENOLIN: International Benchmark on ID Nonlinear Site-Response Analysis-Validation Phase Exercise, Bulletin of the Seismological Society of America, 108(2), 876-900.

Robertson P.K., Woeller D.J. Finn W.D.L., (1992), Seismic cone penetration test for evaluating liquefaction potential under cyclic loading, Canadian Geotechnical Journal, 29(4), 686-695.

Sana H., Nath S.K., Gujral K.S., (2019), Site response analysis of the Kashmir valley during the 8 October 2005 Kashmir earthquake (Mw 7.6) using a geotechnical dataset, Bulletin of Engineering Geology and the Environment, 78(4), 2551-2563.

Seed H.B., Idriss I.M., (1970), Analyses of ground motions at Union Bay, Seattle during earthquakes and distant nuclear blasts, Bulletin of the Seismological Society of America, 60(1), 125-136.

Selçuk L., Aydın H., (2012), Kuvaterner yaşlı alüvyal zeminlerin kuvvetli yer hareketine etkisi: 2011 Van depremleri, Jeoloji Mühendisliği Dergisi, 36(2), 75-98.

Silahtar A., (2018), Isparta havza yapısının jeofizik yöntemler ile modellenmesi ve senaryo deprem sismik tehlike haritalarının hazırlanması, Doktora Tezi, Sakarya Üniversitesi, Fen Bilimleri Enstitüsü, Sakarya.

Sönmezer Y.B., Akbaş S.O., Işı N.S., (2015), Kırıkkale İli Yerleşim Alanı İçin En Büyük İvme, Zemin Büyütmesi ve Hakim Titreşim Periyodu Özelliklerinin Değerlendirilmesi, Gazi Üniversitesi Mühendislik-Mimarlık Fakültesi Dergisi, 30(4), 711-721.

Sönmezer Y.B., Çeliker M., Baş S., (2019), An investigation on the evaluation of dynamic soil characteristics of the Elazig City through the 1-D equivalent linear site-response analysis, Bulletin of Engineering Geology and the Environment, 78(7), 46894712 .

Sönmezer Y.B., Çeliker M., (2020), Determination of seismic hazard and soil response of a critical region in Turkey considering farfield and near-field earthquake effect, Geomechanics and Engineering, 20(2), 131-146.

Stokoe K.H, Choi W.K., Jeon S.Y., Lee, J.J., (2006), Intact Dacite, Tuff and Soil Specimens, Chemistry and Metallurgical Research Replacement (CMRR) Project, Los Alamos National Laboratory, Los Alamos, New Mexico, Geotechnical Engineering Report GR06-1, Civil, Architectural and Environmental Engineering Department, The University of Texas at Austin, Austin, TX.

Şafak E., (2001), Local site effects and dynamic soil behavior, Soil Dynamics and Earthquake Engineering, 21(5), 453-458.

Vucetic M., Dobry R., (1991), Effect of soil plasticity on cyclic response, Journal of geotechnical engineering, 117(1), 89-107.

Yoshida N., (1994), Applicability of conventional computer code SHAKE to nonlinear problem, In: Proceedings of symposium on amplification of ground shaking in soft ground, Tokyo, Japan, ss.14-31.

Yoshida N., Iai S., (1998), Nonlinear site response analysis and its evaluation and prediction, In: 2nd international symposium on the effect of surface geology on seismic motion, Yokosuka, Japan, ss.71-90. 